\title{
El otro como "sí mismo" \\ Una lectura de El retorno del sujeto reprimido de Franz J. Hinkelammert
}

\author{
The other as "self" \\ A reading of The return of the suppressed subject \\ by Franz J. Hinkelammert \\ 0 outro como "o próprio" \\ Uma leitura de 0 Retorno do sujeito reprimido \\ de Franz J. Hinkelammert
}

Fecha de entrega: 15 de enero de 2014 Fecha de evaluación: 20 de abril de 2014 Fecha de aprobación: 15 de junio de 2014

Edwin Cruz Rodríguez

\section{Resumen}

Este artículo reconstruye la concepción del reconocimiento presente en la obra El retorno del sujeto reprimido de Franz J. Hinkelammert. Plantea que para este autor el reconocimiento implica concebir al otro como "sí mismo". Dado que la permanencia de la vida propia está determinada por el respeto hacia el otro inmerso en los ciclos naturales de la vida, un reconocimiento recíproco pasa por comprender que el otro habita en el

Magister en Política del Instituto de Altos Estudios para el Desarrollo. Candidato a Doctor en Estudios Políticos de la Universidad Nacional de Colombia. Premio de ensayo sobre América Latina del Instituto de Estudios Latinoamericanos de la Universidad de Alcalá (2011). Premio internacional de ensayo 2013 (Argentina).Contacto: ecruzro@gmail.com 
"sí mismo", es parte de mí y, en consecuencia, el asesinato es suicidio. Por esa razón, esta teoría del reconocimiento deviene en una ética del bien común. Para desarrollar este planteamiento, el texto se estructura en tres partes. La primera reconstruye la crítica de Hinkelammert a la racionalidad instrumental; la segunda se centra en su concepción del sujeto y la última examina su concepción del reconocimiento y la ética del bien común.

Palabras clave: Franz J. Hinkelammert, sujeto humano, racionalidad instrumental, mercado, reconocimiento, ética, bien común.

\section{Abstract}

This article reconstructs the conception of recognition in the Hinkelammert's El retorno del sujeto reprimido. Author argues that this recognition involves conceiving the other as "himself". Since the permanence of one's life is determined by the respect for others immersed in the natural cycles of life, mutual recognition lies in understanding that the other lives in the "himself" is part of me and therefore, murder is suicide. Therefore, this theory of recognition becomes an ethic of the common good. To develop this approach, the text is divided into three parts. The first reconstructs the critique of instrumental rationality Hinkelammert; the second focuses on his conception of the subject and the latest reviews its conception of recognition and ethics of the common good.

Keywords: Franz J. Hinkelammert, human subject, instrumental rationality, market, recognition, etics, common good.

\section{Resumo}

Este artigo reconstrói a concepção do reconhecimento presente na obra $O$ retorno do sujeito reprimido de Franz J. Hinkelammert. Expõe que para o autor o reconhecimento envolve conceber o outro como " o próprio ". Dado que a permanência da vida própia é determinada pelo respeito para o outro imerso nos ciclos naturais da vida, um reconhecimento mútuo está na compreensão de que o outro mora em 
no "o próprio," faz parte de mim e, portanto, o assassinato é suicídio. Por essa ração, esta teoria do reconhecimento torna-se em uma ética do bem comum. Para desenvolver esta abordagem, o texto é dividido em três partes. O primeiro reconstrói a crítica de Hinkelammert para à racionalidade instrumental; o segundo concentra-se em sua concepção do sujeito e a última examina sua concepção do reconhecimento e a ética do bem comum.

Palavras-chave: Franz J. Hinkelammert, sujeito humano, racionalidade instrumental, mercado, reconhecimento, ética, bem comum.

\section{Introducción}

La extensa obra de Franz J. Hinkelammert ha aportado a diversas corrientes del pensamiento crítico latinoamericano, desde la teoría de la dependencia hasta la teología de la liberación, pasando por la crítica de la economía política ${ }^{7}$. Su pensamiento está atravesado por una permanente preocupación ético-política que se expresa en la forma de una crítica situada del mundo contemporáneo y de la realidad latinoamericana. En los entrecruces de su abigarrada reflexión, particularmente aquella que se reúne en los distintos trabajos que comprende su libro El retorno del sujeto reprimido (2002), podemos encontrar una crítica de los derechos humanos, de la modernidad y de la economía política, pero también una original teoría del reconocimiento ${ }^{8}$. En esta obra, que le valió el ser honrado con la primera edición del Premio Libertador al Pensamiento Crítico que otorga la República Bolivariana de Venezuela, en junio de 2006, existe una inquietud transversal por el reconocimiento recíproco entre sujetos como una condición necesaria para asegurar la reproducción de la vida, en un contexto de crisis sociales y ambientales que amenaza con su extinción en relativamente poco tiempo.

Este trabajo tiene como objetivo la reconstrucción de esa concepción del reconocimiento a partir de una lectura de la obra mencionada. Como es planteado por

7 Una sintesis del desarrollo de su obra en Fernández y Silnik (2011, pp. 65-68).

8 La obra ha conocido tres ediciones. La primera (2002) por la Universidad Nacional de Colombia. Seguidamente (2003), fue publicada como El sujeto y la ley. El retorno del sujeto reprimido por el Departamento Ecuménico de Investigaciones en Costa Rica y, finalmente, la edición venezolana del premio Libertador (2006). 
Hinkelammert, el reconocimiento implica concebir al otro como "sí mismo" -aunque esta expresión no sea usada por el autor-. El otro comprende tanto al sujeto natural y necesitado como a la naturaleza, cuyos ciclos vitales determinan la posibilidad de satisfacer las necesidades y, por consiguiente, la vida. Se trata, entonces, de un "otro extendido" -otra expresión no usada por Hinkelammert- que al mismo tiempo rompe con la concepción abstracta del otro presente en ciertas teorías del reconocimiento y con el antropocentrismo inherente, aunque no necesariamente con el humanismo. Dado que la permanencia de la vida propia está determinada por el respeto hacia el otro inmerso en esos ciclos naturales que funcionan como condiciones de posibilidad de la vida, es necesario un reconocimiento recíproco entre sujetos humanos naturales, lo cual pasa por comprender que el otro habita en el "sí mismo", es parte de mí y, en consecuencia, el asesinato es suicidio. Por esa razón, esta teoría del reconocimiento deviene en una ética del bien común.

La comprensión de esta concepción del reconocimiento pasa por reconstruir a grandes rasgos la crítica de Hinkelammert a la racionalidad instrumental y su concepción del sujeto. Nuestro autor demuestra que el cálculo de utilidad agregado dominante en el mercado -que hace abstracción de la vida y la muerte de los actores así como de los efectos indirectos de sus acciones directas- produce una tendencia autodestructiva que atenta contra la vida humana y la naturaleza. Se trata, por consiguiente, de una violación del bien común, entendido como las condiciones de posibilidad de reproducción de la vida y, por ende, del propio sistema. Es frente al impulso autodestructivo del sistema que emerge el sujeto humano natural para subordinar el cálculo medio-fin a su racionalidad reproductiva determinada por los ciclos naturales de la vida.

\section{La ética del mercado: el otro en un sistema autodestructivo}

Las distintas crisis que enfrenta el mundo contemporáneo tienen raíz, en la perspectiva de Hinkelammert, en las tendencias autodestructivas y la creciente irracionalidad que produce la racionalidad instrumental, expresada en los valores supremos del mercado: la eficiencia y la competitividad. El cálculo de utilidad ha hecho abstracción de la vida y la muerte de los actores del mercado, desconociendo los efectos indirectos de la acción directa que, a nivel agregado, se expresan en las distintas amenazas a la 
vida humana y a la naturaleza9. En esta lógica, el otro es concebido como un actor abstracto del mercado que se erige en una competencia a la que es necesario vencer para maximizar las utilidades.

El punto de partida de la reflexión de Hinkelammert es su crítica de la racionalidad instrumental, que también denomina "cálculo de utilidad", y puede resumirse en esta metáfora:

Celebramos la racionalidad y la eficiencia, sin embargo estamos destruyendo las bases de nuestra vida sin que este hecho nos haga reflexionar acerca de los conceptos de racionalidad correspondientes. Estamos como dos competidores que están sentados cada uno sobre la rama de un árbol, cortándola. El más eficiente será aquel que logre cortar la rama sobre la cual se halla sentado con más rapidez. Caerá primero, no obstante habrá ganado la carrera por la eficiencia (Hinkelammert, 2002, p. 12).

Este ejemplo le sirve a nuestro autor para postular su tesis de la "irracionalidad de lo racionalizado". La racionalización del mundo moderno, que examinara Max Weber como un proceso de "desencantamiento", ha terminado por producir una creciente irracionalidad, con lo que el sentido de la vida, aunado a los proyectos de progreso y desarrollo, han entrado en crisis. El paradigma de ese fenómeno es el imperio del criterio de eficiencia como expresión máxima de la racionalidad instrumental. Se trata de un juicio de hecho que pondera los costos de los medios requeridos para conseguir un fin determinado. Dichos costos son cuantificables en ese equivalente universal que es el dinero: se es eficiente en la medida en que se consiga un fin determinado con costos reducidos (Ibíd., p. 13).

El caso del ser humano sentado en la rama del árbol que corta pone de presente, además, que la lógica de la eficiencia desconoce los efectos indirectos de la acción directa a nivel individual, pero sobre todo las consecuencias que ello tiene en términos globales y agregados. Hinkelammert admite que los actores que realizan el cálculo medio-fin no siempre son conscientes de los efectos indirectos que las acciones fundadas en tal cálculo pueden tener. Sin embargo, también es cierto que existen

9 De acuerdo con Estela Fernández Nadal (2007, p. 202), quien ha trabajado intensamente la obra de Hinkelammert, en la base de este planteamiento se encuentra la interpretación del "fetichismo" en clave marxiana que hiciera en su obra temprana. 
fenómenos recurrentes que informan sobre los efectos agregados que las acciones individuales basadas en la relación medio-fin producen, como la crisis ambiental, y que llevan a que tales efectos indirectos de la acción directa se vuelvan mayoritariamente conscientes (Ibíd., p. 204).

Por esa razón, más que el carácter inconsciente que pueda presentarse, lo que hace que las consecuencias del cálculo de utilidad no sean previstas es el mito de la autorregulación del mercado, pues conduce a una ética de la irresponsabilidad en la que lo único necesario es preocuparse por la maximización de la utilidad individual creyendo que el mercado se encargará de equilibrar las cargas para alcanzar el interés general. Como es bien sabido, tal creencia, que para Hinkelammert es además utópica, se manifiesta en el postulado de la "mano invisible" de Adam Smith. En efecto, para el economista inglés el mercado es la síntesis de los intereses particulares y del interés general:

\begin{abstract}
Comportándose el hombre en mercados, su persecución del interés propio asegura automáticamente el interés común de todos. El mercado es una estructura maravillosa que le quita al hombre toda responsabilidad por el resultado concreto de sus actos, porque automáticamente asegura que este resultado sea directa o indirectamente de provecho para todos. Cuando menos el hombre se preocupa de los otros y de su suerte, mejor asegura a los otros condiciones humanas de su vida. Toda una dialéctica de los contrarios se constituye, que [por] primera vez la había descrito Mendeville anteriormente como: vicios privados, virtudes públicas (Ibíd., p. 160).
\end{abstract}

De esa forma, bajo la ética del mercado lo que debería entenderse como egoísmo, perseguir el interés individual mediante el cálculo de costo y beneficio aun a pesar de los efectos indirectos y perjudiciales que pueda tener sobre el otro, se entiende ahora como una virtud. Los actores individuales y colectivos del mercado únicamente tienen que preocuparse por maximizar sus utilidades, pues de esa forma conseguirán que la mano invisible realice el interés general. De manera que la ética del mercado, aupada por la "circularidad lineal" y el automatismo que lo caracteriza, es erigida como una ética absoluta en la que los seres humanos son irresponsables por los efectos indirectos de sus acciones y son los mecanismos de totalización del sistema los encargados de convertir la búsqueda individual de la maximización de utilidades en interés general. De acuerdo con Hinkelammert (Ibíd., p. 201), así se configura claramente una ética 
de la irresponsabilidad: el mercado tiene como función "compensar todos los efectos indirectos de la acción directa, de una manera tal que sirvan al interés general. El ser humano se puede desentender de estos efectos indirectos, en cuanto actúa en el mercado y respeta las normas de la ética del mercado".

Al contrario de lo que supone la técnica económica dominante, que da por sentado la eficacia del mercado como distribuidor de los efectos indirectos, esa ética del mercado está fundamentada en juicios valorativos. Si bien, al igual que las otras ciencias sociales, la ciencia económica actual postula que únicamente puede pronunciarse en torno a juicios de hecho de acuerdo a la lógica de ensayo y error provista por el concepto de falsación, está sustentada en un juicio de valor, e incluso en un mito, aquel de la mano invisible. El problema, a juicio de nuestro autor, no es que existan el mercado y una ética mercantil sino que, mediante el mito de la autorregulación del mercado, desde Smith se transforma en una ética absoluta fundada en la supuesta coincidencia entre el respeto por las reglas del mercado -la búsqueda de la maximización de la utilidad sustentada en la relación medios-fines-, y el interés general (Ibíd., pp. 202-203).

En esta lógica, el otro aparece como un actor más del sistema de mercado y, por consiguiente, como una competencia o, en el mejor de los casos, como un potencial socio contratante. Junto con la eficiencia, el valor principal de este sistema es la competitividad. Según Hinkelammert, una de las consecuencias de la entronización de la competitividad es la pérdida del sentido de realidad y el consiguiente desplazamiento de la racionalidad al terreno de lo "virtual". Los objetos y productos no son juzgados en función de la satisfacción de alguna necesidad, su valor de uso, sino por el hecho de que su producción sea competitiva, es decir, eficiente. "El trigo, aunque alimente, no debe ser producido si su producción no es competitiva. Un chaleco, aunque caliente o proteja de la lluvia, no debe ser producido si su producción no es competitiva" (Ibíd., p. 12).

En esta realidad virtual el otro es percibido como un competidor, un actor más en la lucha del mercado, instancia que se encarga de definir quién es eficiente y competitivo. Se trata de una demostración tautológica, puesto que siempre es el ganador quien demuestra ser eficiente y ha ganado gracias a su eficiencia. En el mito del mercado, la competencia es la encargada de producir la convergencia no intencional entre las utilidades y cálculos medio-fin de los distintos actores y la realización del interés general, por eso es el valor supremo de la sociedad mercantil. El resultado es una sociedad organizada en torno a la eficiencia y la competitividad, erigidos como criterios 
con la capacidad de decidir sobre la validez de todos los demás valores, afirmando aquellos que considera funcionales y suprimiendo los que no lo son (Ibíd., pp. 13-14).

Paradójicamente, siguiendo esa concepción del otro el cálculo de medios-fines que sustenta la acción racional, al privilegiar la maximización de la utilidad individual, no solo amenaza la vida del actor racional -siguiendo con la metáfora, quien está cortando la rama del árbol en la que se encuentra sentado-, sino que también conduce a arruinar la vida del otro y las condiciones de posibilidad de la vida misma mediante el daño al medio ambiente natural, al desconocer lo que los economistas denominan las "externalidades" del mercado. En últimas, Hinkelammert argumenta que la ética del mercado es equivalente a la ética de la banda de ladrones: para funcionar, tanto el sistema como la banda de ladrones tienen que destruir la vida, pero al destruir la vida también destruyen las condiciones de posibilidad de su propia existencia (Ibíd., p. 209). El efecto indirecto en términos agregados, más allá del mito de la autorregulación del mercado, es la producción de las grandes crisis globales que amenazan la existencia de la vida en el Planeta, la pobreza y la exclusión, el resquebrajamiento de las relaciones sociales en todos los niveles y la crisis ambiental:

\footnotetext{
Esta sociedad existe, pero no es sostenible. Una sociedad es sostenible, cuando la vida humana en ella es sostenible. La sociedad de la ética de los ladrones aparece en cuanto se busca la sostenibilidad del sistema y no de la vida humana. Para hacer sostenible el sistema, hay que sacrificar la vida humana y sacrificándola el propio sistema deja de ser sostenible. Solamente un sistema dentro del cual es sostenible la vida humana, puede ser un sistema sostenible (Ibíd., p. 241).
}

En suma, aunque nadie se proponga como fin la destrucción de la naturaleza y de los seres humanos, la totalización de la racionalidad medio-fin conduce a ella. Se origina por los efectos indirectos e inconscientes de la acción directa en forma agregada, que han sido expulsados del terreno de la racionalidad por el mito de la autorregulación del sistema de mercado.

\section{Una ausencia que grita: el sujeto}

El mercado hace abstracción del cuerpo, y con él de las necesidades, la vida y la muerte de los seres humanos, concebidos en términos abstractos como actores racionales, potenciales propietarios y socios contratantes. Por lo tanto, hacer frente a 
sus tendencias autodestructivas, a la irracionalidad de lo racionalizado, pasa por la irrupción del sujeto humano como criterio subordinante del cálculo de utilidad. El primer paso es una crítica de la razón científica hegemónica.

La concepción dominante de la ciencia, cuyos cimientos fueron sentados entre otros por Max Weber y su fundamentación del principio de la neutralidad axiológica, descansa en el supuesto de que para salvaguardar dicho valor el conocimiento científico únicamente debe pronunciarse sobre los juicios de hecho y, por consiguiente, sobre la racionalidad de los medios para alcanzar determinados fines, pero nunca sobre los valores o fines en sí mismos. En la terminología weberiana, la ciencia se ajusta a la racionalidad con arreglo a fines, puesto que asume la realidad como un medio para la falsación y verificación, pero nunca a una racionalidad con arreglo a valores, no sujetos a esos criterios. Por consiguiente, esta concepción de la ciencia, base de la teoría de la acción racional, está soportada en una relación lineal de la acción con la realidad y desconoce cualquier tipo de relación entre ambas que escape a esta linealidad y toda posibilidad de realizar juicios científicos con validez por fuera de la misma, juicios de hecho que no estén basados en una racionalidad medio-fin (Ibíd., p. 15).

Por ejemplo, en el caso hipotético de los dos hombres que cortan la rama donde están sentados, la ciencia puede pronunciarse hasta decir cuál es la forma más eficiente para cortarla. Puede hacer juicios de hecho. Pero, pregunta Hinkelammert (Ibíd., p. 15), qué pasa cuando uno de ellos cae y muere: se disuelven los medios y los fines. Por consiguiente, esa concepción de la ciencia desconoce que existen juicios de hecho que escapan a la linealidad de la racionalidad medio-fin. Por esa razón, además, la teoría de la acción racional carece de la perspectiva para dar cuenta de la cuestión del sentido de la propia acción racional. El suicidio, cometido de forma consciente o inconsciente, acaba con la posibilidad de tener fines y con el sentido de la vida. Así, de acuerdo con nuestro autor, cortar la rama del árbol solo puede tener sentido si se corta una rama distinta de aquella donde el actor se encuentra sentado, incluso si en esa decisión media un cálculo de medio-fin, como el fabricar leña. En caso de que el actor corte la rama en la que se encuentra sentado, no existe posibilidad de construir sentido, a menos que se haga abstracción del actor, con lo que la acción tendría sentido para otros pero no para él.

Ahora bien, para Hinkelammert, la situación que más ilumina la posibilidad de hacer frente a la irracionalidad de lo racionalizado es aquella en la que el suicidio del actor aparece como un efecto no intencional. La relación medio-fin puede apuntar, en 
efecto, a cortar la rama para producir leña, pero, si se trata de la rama sobre la que el actor se encuentra sentado, "su propia acción contiene objetivamente un sinsentido del cual no tiene conciencia, y que se deriva del hecho de que está cometiendo de modo no intencional un suicidio" (Ibíd., p. 17). Este "sinsentido objetivo" es el que reviste mayor interés, puesto que su comprensión pasa por trascender la racionalidad medio-fin para interpretar la acción.

Para ir más allá de esta racionalidad, el actor debe involucrarse a sí mismo en la interpretación del sentido de su acción, como condición para acceder a la libertad de renunciar a su acción o, por el contrario, cometer intencionalmente el suicidio. En cualquiera de los dos casos, el acto de cortar la rama pierde el sentido dado por la racionalidad instrumental.

Desde el punto de vista de una teoría de la acción racional que se auto-limita al marco de la racionalidad medio-fin es imposible descubrir este sinsentido. Como no involucra al actor en la determinación de los fines de la acción, excluye de su análisis el efecto potencial de los fines realizados sobre la vida del actor. No se trata apenas de un olvido, sino de la constitución de categorías de pensamiento que hacen invisible la problemática de estos efectos. La acción orientada por la eficiencia de la relación medio-fin y la competencia como medio por el cual esta eficiencia es maximizada, aparecen ahora como categorías últimas del pensamiento. En consecuencia, en nombre de la ciencia se excluye el análisis de la relación entre los fines realizados y la vida del actor (Ibíd.).

El punto entonces es que la racionalidad medio-fin, sobre la que descansa el mecanismo de mercado, está incapacitada para dar cuenta de situaciones de hecho en las que se trata de la elección entre vida o muerte. Elecciones enfrentadas a la vida y a la muerte no pueden ser objeto de falsación, de ensayo y error. Aunque tales elecciones se basen en juicios de hecho, tampoco pueden reducirse al cálculo de utilidad. Como afirma Hinkelammert (Ibíd., p. 39), "la vida no es un fin sino la capacidad de tener fines. Por eso tanto vida como muerte escapan a la posibilidad de decidir mediante la racionalidad medio-fin".

La teoría weberiana de la acción racional no puede comprender esta situación, puesto que excluye de su razonamiento y del terreno de la ciencia los juicios de hecho que no dependen del cálculo medio-fin. Desde su perspectiva son juicios con arreglo a valores, 
es decir, juicios de gusto. Por consiguiente, explícitamente desarticula los fines de la vida del actor. Aún más, la teoría de la acción racional supone que solo existen fines parciales sustentados en juicios de hecho y basados en cálculos de utilidad, pero la vida no es uno de estos fines. Los juicios atinentes a vida o muerte son juicios de hecho que no están soportados en un cálculo de medios y fines. La vida del actor no constituye un fin, sino la condición de posibilidad misma de tener fines y, por lo tanto, no puede asegurarse simplemente sometiendo a juicio unos medios supuestamente adecuados:

La vida del actor no puede ser un fin, dado que no puede ser tratada como un fin en competencia con otros. Quien elige la muerte, elige la disolución de todos los fines posibles. Cuando un ladrón nos enfrenta a la amenaza: la bolsa o la vida, no nos enfrenta a una elección entre fines. Si decidimos a favor de la bolsa y en contra de la vida, nos quedamos sin bolsa y sin vida. Hay una única alternativa: afirmar la vida (y entregar la bolsa). La vida es la posibilidad de tener fines, sin embargo no es un fin (Ibíd., p. 18).

Por consiguiente, se requiere ubicar la vida del actor como la condición de posibilidad de tener fines. Esta puesta del actor en el primer plano de la interpretación de la acción implica para Hinkelammert la emergencia del sujeto. Ya no se trata del actor inmerso en el sistema y dominado por el cálculo medio-fin, sino del ser humano natural y necesitado, que subordina y trasciende el cálculo medio-fin en función de su propia vida, dando con ello prelación a la "racionalidad reproductiva del sujeto":

Si el actor que descubre que está cortando la rama sobre la que se encuentra sentado se decide por su vida, actúa como sujeto y se sale de la relación mediofin. Eso no lo hace según un cálculo medio-fin, por cuanto este cálculo no es posible. Él se impone como sujeto a la misma relación medio-fin. Se trata de una racionalidad, si bien no es una racionalidad medio-fin. La racionalidad mediofin es lineal, en tanto que esta otra racionalidad es circular. Es la racionalidad del circuito natural de la vida humana. Ninguna acción calculada de racionalidad medio-fin es racional, si en su consecuencia elimina al sujeto que sostiene dicha acción. Este cálculo lo podemos llamar racionalidad reproductiva del sujeto. Él se refiere a las condiciones de posibilidad de la vida humana (Ibíd., p. 19).

La razón de ser de la racionalidad reproductiva del sujeto descansa en el hecho de que el cálculo medio-fin no tiene en cuenta los efectos, directos e indirectos, consientes e 
inconscientes, que genera la acción racional sobre las condiciones de posibilidad de la vida humana. Así, lo que desde la perspectiva del cálculo de utilidad puede ser racional y eficiente, desde la perspectiva de la racionalidad reproductiva resulta totalmente irracional, en la medida en que pueda afectar las condiciones de posibilidad de la vida del actor en tanto sujeto. Para escapar a la "irracionalidad de lo racionalizado", el sujeto debe realizar un juicio acerca de las consecuencias que la realización de un fin determinado puede tener sobre su vida. Como es obvio, en ese juicio también aparecen cálculos, pero no por ello se trata de un mero cálculo de utilidad, puesto que el sujeto no es un fin sino condición de posibilidad de los fines e incluso el conjunto de fines posibles. Por lo tanto, el sujeto antecede a cualquier fin, tal como el circuito natural de la vida del ser humano antecede al sujeto: "El sujeto determina sus fines, pero sujeto al circuito natural de la vida humana que es condición de posibilidad de su propia vida como sujeto" (Ibíd., p. 20).

El juicio que realiza el sujeto se refiere entonces a su propia sobrevivencia, a la necesidad de situarse en el ciclo natural de su vida. Debe entonces ponderar entre los dos tipos de racionalidad, el cálculo de utilidad y la racionalidad reproductiva, en función de la vida y la muerte. En otros términos, el sujeto se interroga por la compatibilidad entre la relación medio-fin y la reproducción de la vida. Si se tiene como criterio para discernir la elección entre vida y muerte, el error resulta de una "contradicción performativa" entre las dos racionalidades. Esto implica que la racionalidad mediofin se subordina a la racionalidad reproductiva (Ibíd., p. 22).

Con todo, en un sistema donde predomina el cálculo medio fin y donde esta racionalidad se totaliza gracias, entre otras cosas, a la división social del trabajo, no es fácil hacer la distinción necesaria entre los dos tipos de racionalidad. El mercado globalizado resulta en una "circularidad lineal" en la que se hace muy difícil distinguir qué es un medio y qué es un fin, en tanto que medios y fines se presentan inextricablemente unidos y la mayoría de las veces los fines de unos actores son medios de otros (Ibíd., p. 23). La hegemonía del cálculo de utilidad proviene justamente de hacer abstracción de la racionalidad reproductiva del sujeto. Las empresas, por ejemplo, para realizarse como actores competentes en el mercado, están enfocadas en reducir sus costos. El salario está fijado, no con respecto a las necesidades vitales de los trabajadores, sino de acuerdo a las fluctuaciones de la fuerza de trabajo en el mercado; el desempleo, la exclusión, el hambre o la muerte no entran en este cálculo. Algo similar ocurre respecto de la naturaleza, puesto que las empresas enfatizan, por ejemplo, en los costos 
de la extracción de bienes naturales, sin tener en cuenta bajo esta racionalidad las necesidades reproductivas de los ecosistemas naturales donde operan (Ibíd., pp. 2425). Por consiguiente, la lógica mercantil lleva inevitablemente a una contradicción entre el cálculo de utilidad y la racionalidad reproductiva del sujeto:

Frente al criterio del mercado todas las acciones medio-fin son igualmente racionales, aunque en términos de la racionalidad reproductiva sean destructoras. En consecuencia, las actividades destructoras son promovidas por el mercado de la misma manera que las actividades compatibles. Cortar la rama del árbol sobre la que el actor se halla sentado, es tan racional como cortar cualquier otra. El resultado es una tendencia inevitable del mercado hacia la destrucción en términos de racionalidad reproductiva. Es una tendencia tanto a la destrucción de los seres humanos como de la naturaleza, que es condición necesaria para la propia vida humana. Esta tendencia destructiva es la irracionalidad de lo racionalizado... (Ibíd., p. 25).

El encubrimiento de la racionalidad reproductiva se explica en parte por la necesidad de cuantificación del cálculo de utilidad. La racionalidad medio-fin requiere medidas finitas tanto para los medios/costos como para los fines, generalmente utilizando para ello la cuantificación en dinero. Su límite es el infinito, puesto que el cálculo se hace imposible si uno de los elementos tiende al infinito, que de acuerdo con Hinkelammert no corresponde a un número sino al límite de lo concebible como medio o como fin. En contraste, la racionalidad reproductiva del ser humano trabaja siempre con costos que tienden hacia el infinito: la muerte del actor tiene para sí mismo un costo infinito y, por lo tanto, no puede ser comprendida dentro del cálculo medio-fin, a no ser de que se caiga en la "paradoja del vividor" que nuestro autor toma de un texto de Henry Miller: alguien que considera que la vida está tan cara que decide suicidarse para ahorrar lo poco que tiene, lo cual puede resultar perfectamente racional desde la perspectiva del cálculo medio-fin, pero demuestra que esta racionalidad carece de sentido si prescinde de la vida del actor (Ibíd., p. 32).

El cálculo de utilidad trabaja además con un actor abstracto, desprendido del sujeto humano natural y corpóreo concreto. Desde esa perspectiva, el aprendizaje se produce por ensayo y error: se prueban determinados medios hasta que se consigan los más eficientes respecto del fin perseguido. Empero, desde el punto de vista de la racionalidad reproductiva, que ubica en el centro de la escena al sujeto humano natural 
y necesitado, el aprendizaje no puede alcanzarse en virtud de un razonamiento de falsación, puesto que se trata de enfrentar la muerte y evitarla, el fin de la posibilidad de tener fines más que un fin particular. Luego de la muerte no hay para qué experimentar. Se trata de conservar la posibilidad de tener fines como sujeto y, en este sentido, los valores que reivindica la racionalidad reproductiva del ser humano. Este aprendizaje llevaría a la afirmación de valores distintos a los que predominan en el sistema de mercado, como el cuidado, la solidaridad y el respeto de sí y de los otros, incluyendo la naturaleza (Ibíd., 34).

Para Hinkelammert (Ibíd., p. 27), siempre existe un retorno de lo reprimido por la totalización circular del cálculo de utilidad. Las necesidades retornan, la finitud de la vida, las formas alternativas de percibir y concebir tales necesidades también lo hacen pese a la represión que ejercen las formas dominantes de cientificidad. La racionalidad reproductiva del ser humano no deja de existir por el hecho de que sea desconocida en el sistema de mercado. Esta racionalidad no corresponde a un proceso cognitivo, sino que es una exigencia real, una necesidad, de la sostenibilidad de las condiciones de posibilidad de la existencia del sistema, la vida humana y la naturaleza. Se expresa entonces en señales como el desempleo, la pobreza creciente, la crisis de sociabilidad, la crisis ambiental, todos los cuales tienen como rasgo en común el imposibilitar la satisfacción de necesidades (Ibíd., p. 28). El sujeto, que no tiene lugar ni voz en el sistema de mercado, se hace presente, irrumpe, como una "ausencia que grita".

En la concepción del sujeto de Hinkelammert adquiere centralidad el concepto de necesidad. En efecto, no solo se trata de un sujeto humano que se desenvuelve en los ciclos de vida de la naturaleza, sino sobre todo se trata de un sujeto necesitado. Para ser sujeto, preservar su propia vida, el ser humano debe sobreponerse a la racionalidad medio-fin con el objeto de insertarla en el circuito natural de la vida, dando prelación a la racionalidad reproductiva. Por consiguiente, para evitar la irracionalidad de lo racionalizado, los efectos indirectos de la acción directa que amenazan la vida, la necesidad debe erigirse como el criterio fundante de la acción. Por lo mismo, el sujeto necesitado es un sujeto incardinado, su retorno es el retorno de la carne y del cuerpo frente a la irracionalidad del mercado y, de contera, es el retorno de la naturaleza que a su vez es condición de posibilidad para la vida:

El sujeto de la racionalidad reproductiva no es, en sentido preciso, un sujeto con necesidades, sino un sujeto necesitado. Como ser natural vive la necesidad de la satisfacción de su condición de sujeto necesitado. Esta necesidad la 
especifica como fines, los cuales realiza por los medios adecuados al cálculo medio-fin. El ser sujeto necesitado lo obliga a someter estos fines a la racionalidad reproductiva por la inserción de toda su actividad en el circuito natural de la vida humana (Ibíd., p. 21).

Desde esta perspectiva es posible cuestionar el orden de las "preferencias" en el que se sustentan el cálculo de utilidad de acuerdo a la teoría de la acción racional que hoy domina. Dado que el cálculo de medio-fin necesariamente se refiere a elementos finitos y cuantificables en términos de dinero, esta teoría suprime la discusión sobre los valores de uso y por consiguiente sobre las necesidades. El actor del mercado no es un sujeto necesitado, sino un actor con "preferencias" que puede orientar de acuerdo a su racionalidad instrumental. La concepción de utilidad subyacente está soportada en últimas en los deseos del consumidor. En consecuencia, excluye tanto del cálculo de utilidad como de la ciencia al sujeto necesitado inmerso en el circuito natural de la vida (Ibíd., p. 23).

Al ubicar la necesidad en su núcleo, esta concepción del sujeto escapa a cualquier tipo de metafísica, pues no se trata de un sujeto trascendental. El retorno del sujeto reprimido es la vuelta del sujeto humano natural como sujeto concreto de la racionalidad reproductiva de la vida, que se enfrenta a los valores dominantes de la eficiencia y la competencia, generadores de la irracionalidad de lo racionalizado que destruye la vida. Por eso, para nuestro autor la liberación pasa por la recuperación del ser humano como sujeto y no solo como una abstracción, la del actor en el mercado. Frente a las lógicas sistémicas de autodestrucción, es el sujeto humano el que recupera la consideración de conjunto más allá del cálculo de utilidad individual. El fundamento de su acción no es una idea, sino el interés material. El de cada uno en contra de las tendencias autodestructivas del mercado que se producen como consecuencia del agregado de los cálculos medio-fin individuales. Es un sujeto que se hace presente como ausencia en tanto que el mercado solo da lugar a los actores, pero en este proceso de revelación es necesario el reconocimiento del otro.

En la medida en que el actor descubre que el respeto por el otro y por el conjunto en el que se halla es condición de posibilidad de su propia vida, emerge el sujeto. No se trata de hacer un sacrificio por el otro sino de descubrir que "solamente en el conjunto con los otros puede vivir" (Ibíd., p. 348). La relación con los otros, la intersubjetividad, y con la naturaleza, es la condición para llegar a ser sujeto. En este 
sentido, "se sabe en una red, que incluye la misma naturaleza externa al ser humano: que viva el otro, es condición de la propia vida" (Ibíd.). El sujeto, en este sentido, no es un a priori trascendental, pues depende de un proceso en el cual se revela como tal. Es cuando el actor se resiste a las tendencias autodestructivas del sistema que el sujeto se desarrolla. No es un supuesto sino un resultado de tal proceso:

El ser humano como sujeto no es ninguna sustancia y tampoco un sujeto trascendental a priori. Se revela entonces, que el ser sujeto es una potencialidad humana y no una presencia positiva. Se revela como una ausencia que grita y que está presente, pero lo es como ausencia. Como tal la ausencia solicita. Hacerse sujeto es responder a esta ausencia positivamente, porque esa ausencia es a la vez una solicitud. Se trata de una respuesta positiva a la ausencia, sin eliminarla como ausencia. Responde. En este sentido, el ser humano es parte del sistema en cuanto actor o individuo calculante. En cuanto sujeto está enfrentado al sistema, lo trasciende (Ibíd., p. 349).

\section{La ética del reconocimiento y el bien común}

Como puede inferirse, para Hinkelammert, el reconocimiento del otro como sujeto humano natural es condición para la afirmación de sí mismo como sujeto. En otras palabras, es necesario el reconocimiento de la vida del otro para la afirmación de la propia vida. El reconocimiento mutuo no se produce dentro del mercado, como actores racionales en competencia, sino en tanto que sujetos reconocidos mutuamente como seres naturales y necesitados en el marco de la racionalidad reproductiva.

El ser humano tiene que afirmar la vida del otro, para que sea posible afirmar la propia. No se trata del reconocimiento del hablante como hablante en el diálogo. Se trata del reconocimiento entre sujetos que se reconocen mutuamente como seres naturales, cuya condición de posibilidad de su vida es la inserción en el circuito natural de la vida humana. Enfrentado a la vida y a la muerte, nadie se puede salvar solo (Ibíd., p. 35).

Así planteada, esta concepción del reconocimiento opera cuatro desplazamientos en relación con las perspectivas de raigambre hegeliana. Primero, se trata de un reconocimiento que se ubica en el terreno de lo necesario, no en el de lo normativo. 
Segundo, requiere concebir, por decirlo de alguna manera, al otro como "sí mismo" -invirtiendo la célebre fórmula de Ricœur-, puesto que reconocer al otro como sujeto natural necesitado es necesario para que el "sí mismo" (“yo") se mantenga con vida y pueda satisfacer sus necesidades, vale decir, para devenir sujeto. En tercer lugar, esta ética del reconocimiento va más allá del antropocentrismo sin por ello abandonar el humanismo: es una suerte de "humanismo no antropocéntrico" en el que el otro por reconocer es un "otro extendido" que comprende al sujeto humano pero también a la naturaleza que hace posible su vida. En fin, derivado de lo anterior, y como queda claro en su concepción del sujeto, tanto el "sí mismo" o el "yo" como el otro no se conciben en términos de abstracciones o representaciones, sino como cuerpos librados a la finitud de la vida y a la contingencia de la muerte, insertos en los ciclos naturales de la vida.

En la perspectiva de Hinkelammert, la supervivencia de la humanidad en el mundo contemporáneo es, ante todo, un problema ético. Pero se trata de una comprensión de la ética como un presupuesto necesario de la vida humana y no como un conjunto de juicios de valor o principios de acción en la forma de deberes a seguir para conseguir una vida virtuosa. A su juicio, "la reducción de la ética a juicios de valor supone que la ética es una pura decoración de la vida humana, de la cual también se puede prescindir. Hemos prescindido de la ética y nos enfrentamos a la destrucción" (Ibíd., p. 219).

El carácter necesario de esta ética radica en que no es un deber ser o un ideal de buena vida, sino que expresa las condiciones de posibilidad de la vida humana. El reconocimiento mutuo entre seres humanos no es un imperativo, no es lo que deberían hacer, sino lo que de hecho realizan para vivir. Las éticas basadas en ideales de buena vida están fundadas en postulados de cómo se debe vivir y, como tales, son éticas opcionales. Por ejemplo, se puede consumir alcohol o no hacerlo. En cambio, la ética necesaria está formada por aquellos valores que determinan las condiciones de posibilidad de la vida humana, lo cual se enuncia con un juicio de hecho, no producto de una esencia, como podría ser la naturaleza humana, sino del desarrollo de la propia racionalidad inmersa en la acción. En este sentido, el juicio de hecho procede que la vida humana no puede prescindir de la ética:

La ética necesaria se contrapone a la ética de la "buena vida", sin negar a ella sus derechos. Sin embargo, la ética de la buena vida presupone la vigencia de la ética necesaria y no se puede confundir con ella. La ética necesaria es dimensión 
imprescindible de cualquier convivencia humana, y si no se da en un grado suficiente, la propia vida humana se acaba. Por eso la ética necesaria puede ser afirmada por juicios de hecho. Implica aquellos valores sin los cuales la propia convivencia humana -y, por tanto, la sobrevivencia humana- no es posible. Si tal ética no rige, no hay sobrevivencia humana. Se trata evidentemente de un juicio de hecho, que afirma la necesidad de una determinada ética. No afirma el deber de cumplir con esta ética, sino afirma que su cumplimiento es necesario para que el ser humano pueda existir (Ibíd., p. 205).

Para el pensador latinoamericano, en tanto que sujeto el ser humano no tiene unos valores fijados de una vez y para siempre, sino, antes bien, se constituye en el criterio último que permite la existencia de los valores, históricos y cambiantes de acuerdo a la forma como el sujeto se sobrepone a la racionalidad medio-fin. La emergencia del sujeto que subordina el cálculo de utilidad a la racionalidad reproductiva de la vida tiene como punto de partida un juicio según el cual:

Una vida feliz no es posible sin que el otro -incluida la naturaleza- la tenga también. La felicidad no es posible por medio de la destrucción del otro para que viva uno. Al buscarla en la destrucción del otro, se desatan procesos autodestructivos que hacen imposible lograr la meta. No se trata de un cálculo a largo plazo, que a la postre vuelve a repetir el problema que se pretendía solucionar. Se trata de la exigencia de la transformación del sistema de una manera tal, que todas y todos quepan, incluyendo la propia naturaleza externa al ser humano. Esta exigencia trasciende a todos los cálculos de los intereses materiales, pero su cumplimiento es la base de la propia vida humana (Ibíd., p. 350).

En el acto de trascender el cálculo de utilidad el sujeto adquiere conciencia de que sus intereses definidos de acuerdo al cálculo medio-fin se tornan contrarios no solo contra el otro, víctima potencial de los efectos indirectos de su acción directa, sino contra él mismo. Por tanto, para Hinkelammert (Ibíd., p. 369), “este descubrimiento implica a la vez el descubrimiento de que yo soy el otro y el otro soy yo". Por consiguiente, es una concepción del reconocimiento del otro como un ser humano natural y necesitado que no excluye y por tanto es universal, en sentido concreto. Es decir, no es la elevación de una particularidad al lugar de lo universal mediante la forma hegemónica (Laclau, 1996), que constituye el universalismo abstracto, sino aquello que los seres humanos tienen en común pese a sus infinitas diferencias. 
Sin embargo, para Hinkelammert (2002, p. 38), el reconocimiento mutuo conduce a la opción por los sujetos cuya vida está más directamente amenazada. Por eso, el criterio de verdad basado en la elección entre vida y muerte se encuentra en la víctima. No obstante, en cualquier caso se supone la concepción de un "otro extendido" que, sin embargo, no debe confundirse en ningún sentido con el "otro generalizado" de George H. Mead y el interaccionismo simbólico, que da cuenta de las normas dominantes. Es reconocer en el otro un sujeto humano natural que, como tal, es inseparable de su entorno natural, entendido como el medio ambiente necesario para su subsistencia. Por lo tanto, dicho postulado, a su vez, tiene como fondo una ruptura con el antropocentrismo en tanto que el reconocimiento del otro es, al mismo tiempo, el reconocimiento de la naturaleza. Se configura de esa manera un cierto humanismo no antropocéntrico, en tanto que si bien tiene por objetivo último la afirmación del sujeto humano frente a las tendencias autodestructivas del sistema, concibe a ese sujeto desde una perspectiva material como cuerpo arraigado en un ambiente y un ciclo vital naturales:

Antropocentrismo significa, que el ser humano se encuentra en el centro, eso mismo tiene que ser visto en esta perspectiva. El ser humano, que se pone en el centro, tiene que descubrir en ese mismo acto, que él es el otro, y que por tanto, él es el mundo. Si destruye al mundo, se destruye a sí mismo. No solamente: "ama a tu prójimo, tú mismo eres él", sino su extensión al mundo y a la naturaleza externa del ser humano: "ama al mundo (naturaleza); tú mismo eres él (Ibíd., p 369).

Por todo lo anterior, el reconocimiento mutuo es fundamental para la autorrealización del ser humano. La concepción hegemónica de la autorrealización en la sociedad de mercado la hace derivar del cálculo de utilidad. Se trata de ser competitivo y eficiente. De esa manera, el asesinato del otro, al que conduce la racionalidad instrumental al desconocer los efectos indirectos de la acción directa y la irracionalidad de lo racionalizado, se transforma por arte del mito de la mano invisible en el factor determinante de la autorrealización. Se afirman entonces valores como el individualismo, el egoísmo y la competencia. Por el contrario, si se parte de que la vida del otro es necesaria para mi propia vida, se impone la conclusión de que no existe la autorrealización sin contar con el otro:

Que el otro viva, es condición de posibilidad de mi vida. Al afirmar yo esta relación, me autorrealizo. Implica excluir el asesinato como medio de la 
autorrealización. Aparece un principio de la autorrealización, que sigue de un postulado de la razón práctica, que sostiene: asesinato es suicidio (Ibíd., p. 365).

Esta última proposición da cuenta de la comprensión del otro como "sí mismo": asesinar al otro implica destruir las condiciones de posibilidad de "mi" propia vida, es decir, suicidio. Pero tal comprensión hace necesaria una distinción adicional entre los cálculos del actor en el mercado y la racionalidad reproductiva del sujeto humano. La racionalidad medio-fin con la que opera el actor del mercado defiende intereses parciales, sean de individuos o grupos que, como se ha mencionado, en su forma agregada generan tendencias autodestructivas. En contraste, aunque el sujeto también reivindica unos intereses, no lo hace desde el cálculo de utilidad, sino desde la intersubjetividad que se produce una vez se comprende que las amenazas a la vida del otro y a la naturaleza es una amenaza a la vida propia.

\begin{abstract}
Si África se abandona, yo sé como sujeto, que eso me afecta, a mí y mis hijos, aunque no sé cómo. Si me solidarizo, defiendo no solo a los africanos, defiendo a mí también (sic). Calculadamente, una afirmación como esta no tendría sentido. Pero no se trata de sacrificarse por el otro, sino de reivindicarse como sujeto. Eso no se puede sin reivindicar al otro. De esta reivindicación nace la solidaridad en cuanto praxis, porque al reivindicarse como sujeto la persona se reivindica en el conjunto de los otros. El otro está en mí, yo estoy en el otro (Ibíd., p. 245).
\end{abstract}

Esta visión del otro como "sí mismo", en últimas, conlleva a una concepción del bien común. En la Edad Media, el bien común se concibió de una manera esencialista de acuerdo a los desarrollos de la tradición aristotélica que presuponían una naturaleza humana. En la modernidad, como se ha dicho, se supuso que el equilibrio de mercado podría conciliar el interés particular con el general, lo que vendría a reemplazar la vieja concepción del bien común, pese a que realmente constituya una tendencia autodestructiva de la vida y la naturaleza. En el pensamiento de Hinkelammert, la ética necesaria y el reconocimiento mutuo están vinculados a la emergencia de otro concepto de bien común, que se explica como consecuencia de la experiencia de afectación que las "externalidades" del mercado producen en la naturaleza y la vida humana.

La ética del bien común resulta de la experiencia y no de una derivación apriorística a partir de naturaleza humana alguna. Experimentamos el hecho 
de que las relaciones mercantiles totalizadas distorsionan la vida humana y, por consiguiente, violan el bien común. La misma experiencia de la distorsión hace aparecer el concepto de bien común, en cuanto este se hace presente como resistencia. Pero eso es una experiencia a partir del afectado por las distorsiones que el mercado produce (Ibíd., p. 97).

Como producto de la experiencia, este concepto del bien común es histórico, no procede de una esencia a priori como era el caso en la tradición tomista. Por consiguiente, sus exigencias y valores se transforman al compás de las distorsiones que crean los efectos del mercado sobre la vida y la naturaleza. Las exigencias por la corrección de las distorsiones del mercado constituyen el núcleo del bien común (Ibíd., p. 98). El bien común se constituye, entonces, en un proceso dialógico, en su relación permanentemente conflictiva con el sistema de mercado. El cálculo de utilidad agregado produce una tendencia autodestructiva que empieza por atentar contra la vida humana y la naturaleza. Se trata, por consiguiente, de una violación del bien común, entendido como las condiciones de posibilidad de reproducción de la vida y, por ende, del propio sistema:

\begin{abstract}
Lo que se puede afirmar solamente es que el bien común y lo que exige, se revela a partir de las tendencias autodestructivas del sistema en su inercia. El bien común entonces formula positivamente lo que es implícito en la solicitud del sujeto ausente. No tiene ninguna verdad absoluta previa, sino que surge a partir de una interpretación de la realidad a la luz de la solicitud del sujeto ausente (Ibíd., p. 349).
\end{abstract}

Para Hinkelammert, hoy existe un desequilibrio sistémico en el que han terminado por primar las lógicas autodestructivas del sistema. No se trata entonces de suprimir el sistema, puesto que son sus distorsiones las que hacen posible la emergencia del bien común, sino de alcanzar un equilibrio, lo que a su vez pasa por subordinar la lógica de la eficiencia, la irracionalidad de lo racionalizado, a la racionalidad reproductiva del ser humano. El problema es la mediación entre las lógicas de reproducción de la vida y la lógica sistémica, por lo tanto ninguna de las polaridades debe suprimirse:

Esta ética del bien común surge en relación del conflicto con el sistema que se constituye por medio del cálculo de interés propio, pero a la vez tiene que ser 
una ética del equilibrio y no de eliminación del otro polo del conflicto. Sería fatal enfocar esta ética desde el punto de vista de la abolición del mercado y del dinero. Tiene que ser una ética de la resistencia, la interpelación y la intervención. Si las relaciones mercantiles se derrumbaran, ella tendría que correr para restablecerlas, pues únicamente se puede interpelar relaciones mercantiles que de alguna manera también funcionan. Esto mismo vale al revés. Si no existe esta resistencia e intervención, la interpelación práctica del sistema no tendrá lugar y este estará por caer. Se desmoronará por su propia lógica (Ibíd., p. 98).

En otras palabras, el sistema requiere de las resistencias para corregir su tendencia autodestructiva. Las resistencias conducen al sistema a integrar sus exigencias, que inicialmente son percibidas como distorsiones, como condición para subsistir (Ibíd., p. 210). Las resistencias hacen que el sistema integre e incluya lo que en un momento dado emerge como el bien común, interpelan al sistema para transformarlo. Ahora bien, la historicidad del bien común no implica que este carezca de valores concretos, entendidos como aquellos que en cierto momento se constituyen en condiciones de posibilidad para garantizar los ciclos naturales de la vida humana y de la naturaleza. El reconocimiento mutuo entre sujetos humanos y entre estos y la naturaleza no se fundamentan en cálculos de utilidad, sino en el hecho de que son la base de la vida. Nuevamente, "su principio es: nadie puede vivir, si no puede vivir el otro" (Ibíd., p. 99).

En últimas, la ética del bien común se constituye como una ética de la responsabilidad. El sujeto humano es responsable de los efectos indirectos de sus acciones directas, al menos en el grado en que sea posible tomar conciencia de ellos, y no puede inculpar a los mecanismos despersonalizados del mercado. Esta ética comprende también la toma de conciencia sobre tales efectos y el imperativo de enfrentarlos (Ibíd., p. 212). Se trata de una responsabilidad en común, no solo individual, no es una ética privada, sino atinente a las condiciones que posibilitan la vida humana (Ibíd., p. 222).

\section{Corolario}

Uno de los ejes más significativos en la obra de Franz J. Hinkelammert es el constituido por la ética del reconocimiento y del bien común. Hemos propuesto una reconstrucción de esta teoría como la necesidad de concebir al otro en tanto que "sí mismo". El otro al que se hace referencia corresponde a un sujeto humano inmerso en los circuitos naturales de la vida, al que es necesario reconocer como tal porque 
su existencia, y la de la propia naturaleza, son condiciones de posibilidad de la propia vida. El otro es un "otro extendido", pues vincula la naturaleza y sus ciclos vitales necesarios para la satisfacción de las necesidades, y el reconocimiento de ese otro configura un "humanismo no antropocéntrico", que es un universal concreto en tanto que no excluye a nadie pero no se trata de una abstracción que erige lo particular en universal sino de la base material que posibilita la vida, de lo que los seres humanos tienen en común y se ve amenazado en un momento determinado.

De esa forma, el reconocimiento mutuo es además una condición para que el actor del mercado, la abstracción con la que opera la racionalidad medio-fin del sistema, devenga sujeto humano natural, pues de esa manera es capaz de asumir la finitud de su vida que así se convierte en el límite de posibilidades del cálculo de utilidad. El sujeto emerge entonces como "ausencia que grita" frente a las tendencias autodestructivas del sistema, pone de presente el bien común, concebido como aquello que es amenazado por el desequilibrio sistémico, y formula unas solicitudes que hacen que ese bien común histórico y contingente sea asumido por el sistema.

Se trata, en fin, de una ética necesaria, en tanto que no se trata de actuar de acuerdo a una elección calculada o un deber frente a un ideal de vida buena, sino de aquello que garantiza la reproducción de la vida en el Planeta. Así pues, frente a la ética de la irresponsabilidad que opera en el mercado, de acuerdo con la cual los actores únicamente deben preocuparse por maximizar sus utilidades en tanto que la competencia, la mano invisible, se encargará mágicamente de resolver las "externalidades", se configura una ética de la responsabilidad y un sujeto capaz de hacerse consciente de los efectos indirectos de la acción directa y responsable por los daños que su acción racional puede acarrear sobre el otro y la naturaleza.

\section{Referencias}

Fernández, E. (2007). La búsqueda de alternativas a la democracia capitalista. Franz Hinkelammert y la crítica de la racionalidad formal, en G. Hoyos Vásquez (ed.). Filosofía y teorías políticas entre la crítica y la utopía. Buenos Aires: Clacso.

Fernández, E., y Silnik, G. (2011) El pesimismo esperanzado. Entrevista a Franz Joseph Hinkelammert. Crítica y Emancipación, 3(5), 63-77. 
Hinkelammert, F. (2002). El retorno del sujeto reprimido. Bogotá: Universidad Nacional de Colombia.

Laclau, E. (1996). Why do Empty Signifiers Matter to Politics? En Emancipations. London: Verso. 